\title{
oints
}

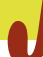

\section{Analysis of complications of reverse total shoulder arthroplasty}

\author{
RAFFAELE RUSSO ${ }^{1}$, GIUSEPPE DELLA ROTONDA², MICHELE CICCARELLI', \\ FABIO CAUTIERO 1
}

1 Ospedale dei Pellegrini, Naples, Italy

2 Department of Orthopaedics, Ruesch Clinic, Naples, Italy

\begin{abstract}
Purpose: the aim of this study was to analyze complications of reverse total shoulder arthroplasty (RTSA) used to treat different shoulder diseases. Methods: from March 2000 to March 2013, 195 RTSA were implanted by the senior Author. The indications for reverse prosthesis surgery were secondary osteoarthritis $(\mathrm{OA})$ in 49 cases, irreparable rotator cuff tear (RCT) in 48 cases, and complex humeral fractures in 75 cases, while 19 were patients requiring surgical revision for first prosthesis implant. We used different prostheses with different designs. Results: the clinical and radiological results of all the patients were analyzed retrospectively at an average follow-up of 7 years. The cases were divided into four groups on the basis of the diagnosis and complications were classified as perioperative, postoperative, or late. The mean total Constant score improved from 28 to 69 points in the OA group; from 21 to 70.8 points in the irreparable RCT group, to 76.4 in the fracture group, and from 16.6 to 59.8 points in the revision group. Scapular notching was observed in 59 cases $(30.2 \%)$. Thirtythree other complications $(16.9 \%)$ were observed, namely: hematomas $(n=3)$, instability of the humeral component $(n=1)$, scapular spine fractures $(n=2)$, ulnar nerve deficit $(\mathrm{n}=2)$, long thoracic nerve palsy $(n=2)$, deep infections $(n=2)$, periprosthetic fractures $(n=6)$, glenoid fractures $(n=2)$, implant loosening $(n=2)$, anterior deltoid muscle deficiency $(n=2)$ and periarticular heterotopic calcifications $(n=9)$.
\end{abstract}

\section{Corresponding Author:}

Giuseppe Della Rotonda, MD

Department of Orthopaedics, Ruesch Clinic

Viale Maria Cristina di Savoia, 80100 Naples, Italy

E-mail: peppedellarotonda@gmail.com
Conclusions: the rates of complications, especially fractures, reported in the present study were lower than those reported in the current literature. Level of evidence: Level IV, therapeutic case series.

Key Words: reverse shoulder prosthesis, complications, results, surgical technique.

\section{Introduction}

The original concept of the modern reverse total shoulder arthroplasty (RTSA) for eccentric shoulder ostheoarthritis (OA) was first described by Grammont et al. in 1993 (1). Over the past decade, this prosthetic model has found novel indications for many other pathologies, such as complex proximal humeral fractures and their sequelae, irreparable rotator cuff tear (RCT) with or without pseudoparalysis, and hemiimplant or total implant failures (2). Recent studies showed a high rate of complications, ranging from 14 to $75 \%$ (3), mainly reported during the learning phase, but also encountered by skilled surgeons because of objective technical difficulties and limitations of the prosthesis design.

The aim of this study was to analyze complications arising in RTSA used to treat different shoulder diseases.

\section{Methods}

From March 2000 to March 2013, 195 RTSA (4 bilateral) implants were implanted in 191 patients (66 males and 125 females; mean age: 67 years, range: 3695 years) by the senior Author (RR). Of these, 172 were patients receiving primary implants and 19 were patients undergoing revisions. One patient was oper- 
ated on twice due to a trauma. The indications for RTSA were secondary OA in 49 cases, irreparable RCT in 52 cases, complex humeral fractures in 75 cases, and failed shoulder arthroplasty in 19 cases. We excluded from this series patients treated with RTSA for fracture sequelae (analyzed in another study).

During the preoperative assessment, all the cases were studied using computed tomography in order to identify the glenoid shape and orientation, and fatty degeneration of the rotator cuff muscles.

Until 2012, this surgery was performed under general anesthesia, whereas in the past two years regional block anesthesia has been used. The transdeltoid approach was used in the first 2 cases, after which we switched to the deltopectoral approach, which allows easier access to and management of the glenoid.

In cases of failed rotator cuff repair associated with OA we often encountered stiff tissues which made the implantation technically difficult. In 4 such cases, scar tissue surrounding the humeral head and the metaphyseal bone had to be carefully detached to allow access to the joint dislocation and proper execution of the head osteotomy.

Different prostheses were used: SMR Reverse (Lima, Sandonà di Piave, Italy) in 167 cases, Delta III Reverse (Depuy, Warsaw, IN, USA) in 10 cases, Delta Extend (Depuy) in 6 cases, Aequalis Reversed (Tornier, Edina, MN, USA) in 5 cases, Anatomical Shoulder Inverse/ Reverse (Zimmer, Warsaw, IN, USA) in 5 cases, and Equinoxe Reverse System (Exactech, Gansville, FL, USA) in 2 cases.

A cemented humeral stem was implanted in 16 procedures $(8.2 \%)$ and a cementless stem was used in all the others. As regards the amount of humeral retroversion, $30^{\circ}$ was given in 8 procedures where the glenoid had more antiversion in order to avoid mechanical impigment and $20^{\circ}$ in all the others. The baseplate was systematically implanted with an inferior tilt of $5^{\circ}$ to $10^{\circ}$. The glenosphere diameter was $36 \mathrm{~mm}$ in 191 cases $(98 \%)$ and $42 \mathrm{~mm}$ in 4 cases $(2 \%)$.

The subscapularis tendon was reattached to the anterosuperior edge of the anatomical neck using transosseus sutures in 176 procedures $(90.2 \%)$; in 15 $(7.6 \%)$ the tendon was irreparable, and in $4(2 \%)$ we performed a latissimus dorsi transfer (modified L'Episcopo technique) due to an associated irreparable tear of the teres minor.

Since 2005, we have used RTSA to treat patients aged 70 years or more presenting with proximal humeral fractures. Tuberosities around the humeral neck prosthesis are preserved and reconstructed with knots trying to restore them to an anatomical position. The surgical technique used was the "puzzle piece" described by Brems (4) for hemiarthoplasties, which we adapted to RTSA and modified according to the "bone collar and tie" (BCAT) technique (5). The stem was implanted with a retroversion of between 0 and $20^{\circ}$ depending on the degree of glenoid version trying to ensure that both articular components lie on the same plane, especially the axial one. Patients treated for fractures were immobilized in a sling with arm in adduction for four weeks, as opposed to two weeks in the case of patients with $\mathrm{OA}$.

The results were evaluated on the basis of the Constant score normalized for age. All baseline data and results, including complications, were collected in a dedicated database.

\section{Results}

The cases were followed up for an average of seven years. The results and complications were analyzed by dividing the patients into four groups according to their pathology: irreparable RCT, OA, fractures and revisions. The total Constant score in the OA group improved from 28 points at the baseline evaluation to 69 points (range: $32-77$ points) at follow-up; in the irreparable RCT group, the Constant score increased from 21 points at baseline to 70.8 (range: 30-77.2 points) at follow-up; in the fracture group the Constant score at follow-up was 76.4, and in the revision group it rose from 16.6 to 59.8 points.

Complications were classified as: perioperative, postoperative, late and radiological changes. The 195 RTSA procedures gave rise to 28 complications $(14.3 \%)$ : 7 perioperative, 13 postoperative, and 8 late (Tab. 1).

No perioperative complications were observed in the patients treated for irreparable RCT or OA, while postoperatively we observed 3 cases of hematoma with seroma treated with cryotherapy and antibiotics, 1 case of ulnar nerve dysfunction, 1 deep infection treated with an antibiotic spacer left in place for two years and then re-operated (Fig. 1), 3 cases of periprosthetic ossification without significant loss of function (Fig. 2), and 2 cases of scapular spine fracture, healed with conservative treatment. Late compli- 
Table 1. Subgroup analysis of complications of RTSA according to pathology.

\begin{tabular}{|c|c|c|c|c|c|}
\hline Groups & $\begin{array}{l}\text { Perioperative } \\
\text { complications } \\
(\mathrm{N}=7)\end{array}$ & $\begin{array}{l}\text { Postoperative } \\
\text { complications } \\
(\mathrm{N}=13)\end{array}$ & $\begin{array}{l}\text { Late complications } \\
(\mathrm{N}=8)\end{array}$ & $\begin{array}{l}\text { Radiological } \\
\text { finding }\end{array}$ & $\begin{array}{l}\text { Overall } \\
\text { Complications }\end{array}$ \\
\hline $\begin{array}{l}\text { Irreparable } \\
\text { RCTs/OA } \\
(\mathrm{N}=97)\end{array}$ & 0 & $\begin{array}{l}3 \text { hematomas }(3 \%) \\
1 \text { ulnar neuropathy }(1 \%) \\
1 \text { deep infection }(1 \%) \\
3 \text { heterotopic ossifications }(3 \%) \\
2 \text { scapular spine fractures }(2 \%)\end{array}$ & 1 metal-back mobilization (1\%) & $\begin{array}{l}26 \text { grade I scapular } \\
\text { notching }(26.8 \%) \\
19 \text { grade II scapular } \\
\text { notching }(19.5 \%) \\
5 \text { grade III scapular } \\
\text { notching }(5.1 \%)\end{array}$ & $11(10.8 \%)$ \\
\hline $\begin{array}{l}\text { Fractures } \\
(\mathrm{N}=75)\end{array}$ & $\begin{array}{l}3 \text { humeral shaft } \\
\text { fractures }(4 \%) \\
2 \text { glenoid fractures }(2.6 \%) \\
2 \text { deep damage anterior } \\
\text { deltoid bundle }(2.6 \%)\end{array}$ & $\begin{array}{l}1 \text { instability }(1.3 \%) \\
1 \text { ulnar neuropathy }(1.3 \%)\end{array}$ & 0 & $\begin{array}{l}9 \text { scapular } \\
\text { notching }(12 \%) \\
6 \text { heterotopic } \\
\text { ossifications ( } 8 \%)\end{array}$ & $9(12 \%)$ \\
\hline $\begin{array}{l}\text { Revisions } \\
(\mathrm{N}=19)\end{array}$ & 0 & $\begin{array}{l}1 \text { upper limb SRD } \\
\text { and thoracic } \\
\text { long nerve palsy }(5.2 \%)\end{array}$ & $\begin{array}{l}3 \text { humeral fractures }(15.7 \%) \\
1 \text { late deep infection }(5.2 \%) \\
1 \text { thoracic long nerve palsy }(5.2 \%) \\
1 \text { aseptic mobilization }(5.2 \%)\end{array}$ & 0 & $7(36.8 \%)$ \\
\hline
\end{tabular}

RCT: rotator cuff tear; OA: osteoarthritis; SRD: sympathetic reflex dystrophy.

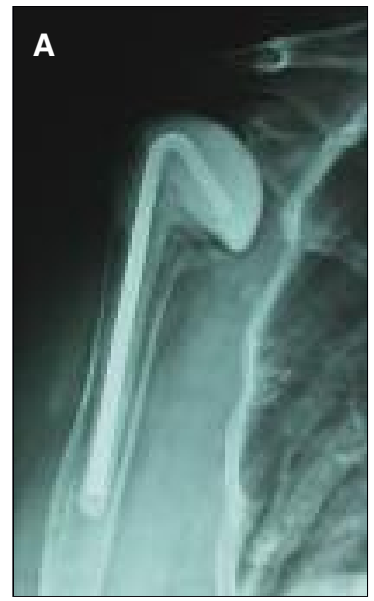

Fig. 1. A: Postoperative X-ray of the humeral spacer after removal of the infected prosthesis. B: Postoperative X-ray after TSRA revision.

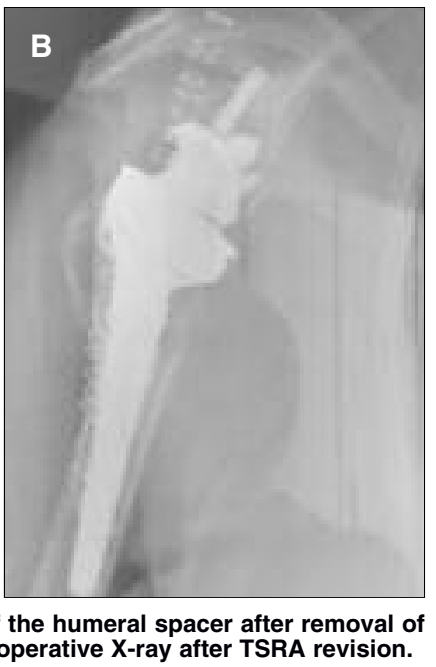

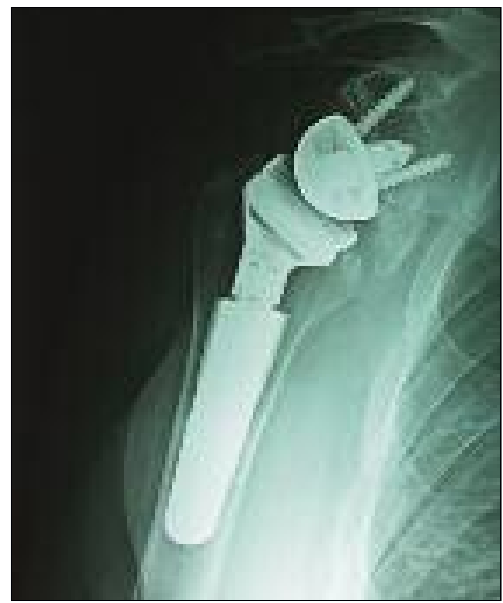

Fig. 2. Periprosthetic ossification of the medial compartment without significant loss of motion. cations were related mainly to scapular notching. According to Nerot's classification, we observed grade I notching in 26 cases, grade II in 19 cases, and grade III in 5 cases; a single case of glenoid baseplate loosening was successfully managed surgically.

In the fracture group, we observed, as perioperative complications, 3 longitudinal fractures of the humeral shaft treated with cerclages, 2 glenoid fractures fixed with screws and cancellous bone graft taken from the humeral head, and 2 cases of deep damage to the anterior bundle of the deltoid muscle. We encountered 2 postoperative complications: humeral instability and ulnar neuropathy, which settled down after one year. Scapular notching and heterotopic ossifications (Fig. 3) were present at medium- to long-term followup in 9 and 6 cases, respectively.

In the revision group, there were no perioperative complications, while we observed 1 case of postoperative sympathetic reflex dystrophy (SRD) of the upper limb with pain and thoracic long nerve palsy, and at 


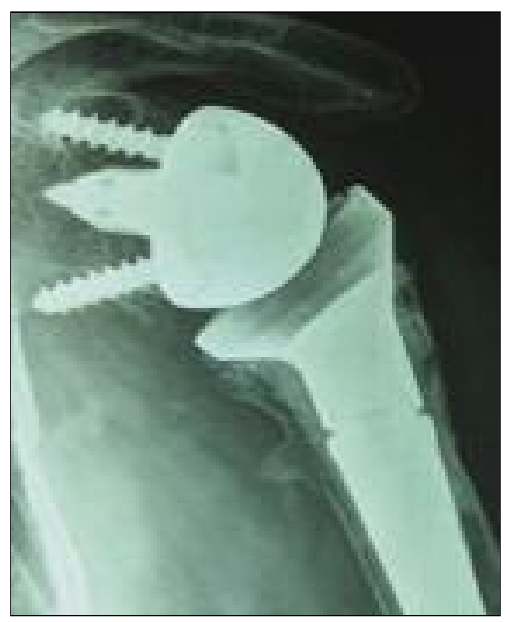

Fig. 3. Four-part fracture treated with reverse prostheses and PPT (Puzzle Piece Technique) with cemented stem X-ray nine years of X-ray at nine years of follow-up shows no signs of scapular notching, subtotal great tuberosity reabsorption, small ossification of pectoralis major tendon and asymptoma tic reactive bone tic reactive bone cyst around the superior screw of the glenoid baseplate.
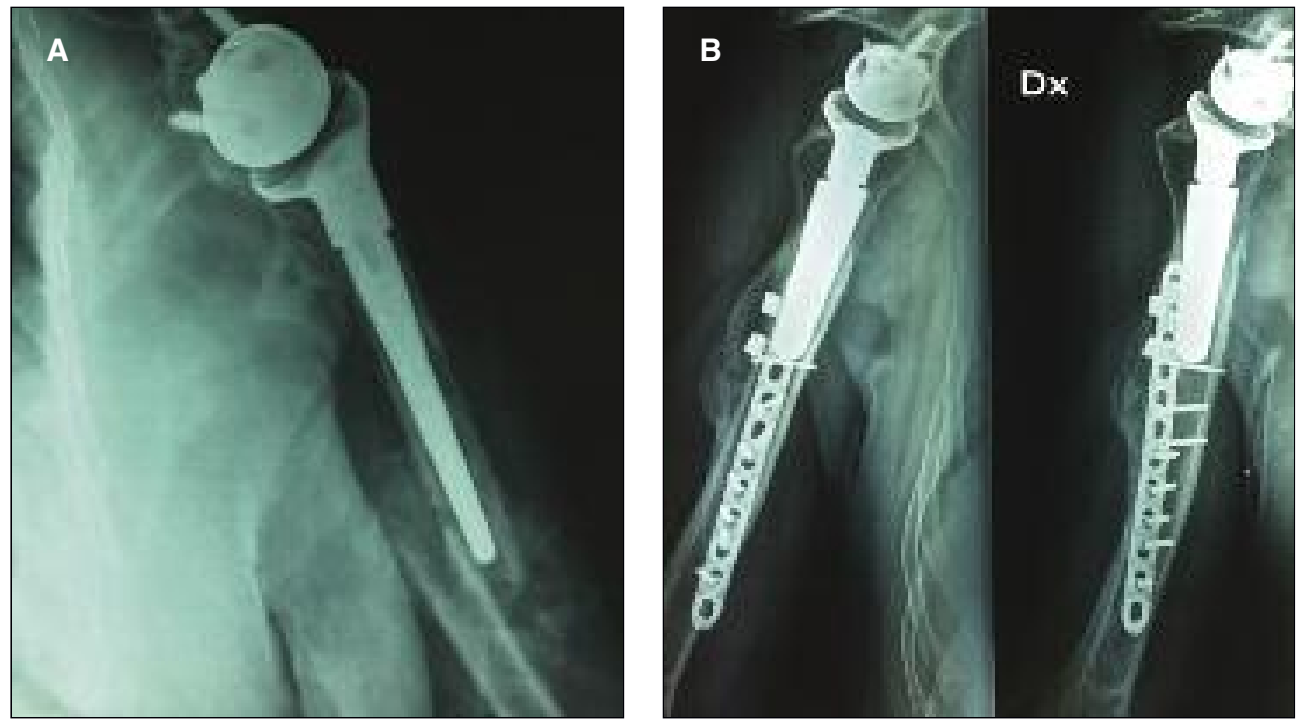

Fig. 4. A: A woman with a traumatic peri-prosthetic humeral fracture (type $B$ fracture according to the Wright and Cofield classification) occurred seven years after reverse implant and treated nonoperatively. X-ray shows that fracture healed three months later. B: Healing of a type A fracture treated with plate and cerclage.

\section{Discussion}

Reverse total shoulder arthroplasty was originally described by Grammont as a method for treating eccentric shoulder arthropathy (1). Over the past decade, the indications for RTSA have become much broader, and the procedure is currently used to treat irreparable RCT, complex fractures and fracture sequelae, to revise anatomical or resurfacing replacements, to treat avascular necrosis of the humeral head in the elderly, as a method of shoulder reconstruction in rheumatoid arthritis, and to treat chronic shoulder dislocations in the elderly (3). However, in the recent literature, considerable attention is paid to the complications associated with RTSA (6). In our experience, the use of RTSA in complex humeral fractures gave better results than those reported in the literature, in terms of complications such as: secondary instability, infections, loss of movement, upper limb SRD and heterotopic ossifications (7). We believe that this success, especially in fractures, can be attributed to different managerial factors such as a quick treatment (at maximum 5 days in fracture cases), gentle soft tissue manage-

medium- to long-term follow-up 3 traumatic fractures of the humerus (Fig. 4), 1 deep infection, 1 thoracic long nerve palsy, and 1 aseptic mobilization after 9 years.

Overall, the re-operation rate for complications was $16 / 172(9.3 \%)$ in the primary implants and 2/19 $(10.5 \%)$ in the revision cases. Revision of the prosthetic implant was performed in 4 cases.

One patient was re-operated twice, undergoing a latissimus dorsi transfer during the first revision surgery and then, following a traumatic event, a revision of the prosthesis. ment, uncemented prosthesis implant also in the elderly, quick surgical time and a proper CT-scan study. In consideration of function results we had particular attention to preserve and reconstruct tuberosities using the "puzzle piece technique" described by Brems (4) for hemiarthoplasties, but applied by us to RTSA and modified according to the Bone collar and Tie technique (BCAT) (5) in order to preserve external rotation activity of the teres minor and residual infraspinatus when tuberosities have healed around the implant. We recently compared two groups of patients in whom tuberosities were reconstructed 
according to the Brems and BCAT techniques (5-8). The BCAT technique resulted in better clinical function particularly in abduction and external rotation. We also observed a lower rate of deep infections (1\%) than those reported in literature (up to 10\%) (9). We performed all RTSA implants in a standard operating theater without ultraviolet light or positive pressure ventilation and using perioperative antibiotic administration. Some studies underline the importance of using an antibiotic-impregnated cement (10) and chlorhexidine lavage during the procedure (11), but none of these measures were used in most of our patients.

A high rate of RTSA instability (from 2.4 to $31 \%$ ) has been reported in the literature (12), while our series included only one case $(0.5 \%)$ treated for trauma with a complex humeral nonunion. The deltopectoral approach, in our opinion, allows easy access to the glenoid for the management of bone defects and replacement.

Another key point, in order to avoid a secondary instability, is to reattach the lesser tuberosity, especially in cases of OA and RCT (13), although in the Literature some studies reported a good results without subscapularis reattachment (14).

We had 3 cases of perioperative humeral shaft fracture treated successfully with cerclages. In the RCT group we had 1 case of baseplate rupture due to a severe trauma which was treated with a revision baseplate and iliac crest bone graft.

The scapular notching rate in all our cases, and especially in the fracture group, was lower than reported by others in the literature (15). We believe that good balancing of the anterior and posterior tendons could be the key point to avoid this complication.

At follow-up we didn't find a loss of function as reported by Favard (16) in his series and we guess that this is because we put the glenosphere with a $10^{\circ}$ inferior tilt. The strength of our series is that all patients were treated by the same senior surgeon, in the same hospital, in $98 \%$ of cases we implanted a $36 \mathrm{~mm}$ glenosphere and an uncemented prosthesis also in fractures group.

A limitation of this study is the absence of a group treated using other techniques.

In conclusion, the rates of complications reported in the present study were lower than those reported in the current literature, especially in fracture cases.

\section{References}

1. Grammont P, Trouilloud P, Laffay JP, Deries X. Etude et realisation d'une nouvelle prothese d'epaule. Rheumatologie. 1987;39:407-418.

2. Hatzidakis AM, Norris TR, Boileau P. Reverse shoulder arthroplasty indications, technique, and results. Techniques Shoulder Elbow Surg. 2007;16:e55.

3. Sershon RA, Van Thiel GS, Lin EC, McGill KC, Cole BJ, Verma NN, Romeo AA, Nicholson GP. Clinical outcomes of reverse total shoulder arthroplasty in patients aged younger than 60 years. J Shoulder Elbow Surg. 2014;23:395-400.

4. Brems JJ. Shoulder arthroplasty in the face of acute fracture: puzzle pieces. J Arthroplasty. 2002;17(4 Suppl 1):32-35.

5. Ciccarelli M, Russo R, Della Rotonda G, Cautiero F. The "Bone-Collar-and-Tie" (BCAT). J Bone J Surg Br. 2013;93:202.

6. Walch G, Wall B, Mottier F. Complications and revision of the reverse prosthesis, a multicenter study of 457 cases. In: Walch G, Boileau P, Molè D, Favard L, Lévigne C, Sirveaux F, editors. Reverse Shoulder Arthroplasty. Montpellier, France: Sauramp Medical. 2006;335-352.

7. Martin TG, Ianotti JP. Reverse total shoulder arthroplasty for acute fractures and failed management after proximal humeral fractures. Orthop Clin North Am. 2008;39:451-457.

8. Russo R, Cautiero F, Fontanarosa A, Rotonda GD, Valerio G. Reconstruction techniques in comparison for reverse shoulder trauma prosthesis in the elderly: a follow-up between 2 and 4 years. Arch Orthop Trauma Surg. 2015;135:905-912.

9. Cheung EV, Sperling JW, Cofield RH. Infection associated with hematoma formation after shoulder arthroplasty. Clin Orthop Relat Res. 2008;466:1363-1367.

10. Nowinski RJ, Gillespie RJ, Shishani Y, Cohen Walch GA, Gobezie R. Antibiotic-loaded bone cement reduces deep infection rates for primary reverse total shoulder arthroplasty: a retrospective, cohort study of 501 shoulders. J Shoulder Elbow Surg. 2012;21:324-328.

11. Brown NM, Cipriano CA, Moric M, Sporer SM, Della Valle CJ. Dilute betadine lavage before closure for the prevention of acute postoperative deep periprosthetic joint infection. J Arthroplasty. 2012;27:27-30.

12. Groh GI, Groh GM. Complications rates, reoperation rates and the learning curve in reverse shoulder arthroplasty. J Shoulder Elbow Surg. 2014;23:388-394.

13. Edwards TB, Williams MD, Labriola JE, Elkousy HA, Gartsman GM, O'Connor DP. Subscapularis insufficiency and the risk of shoulder dislocation after reverse shoulder arthroplasty. J Shoulder Elbow Surg. 2009;18:892-896.

14. Grassi FA, Zorzolo I. Reverse shoulder arthroplasty without subscapularis repair for the treatment of proximal humeral fractures in the elderly. Musculoskelet Surg. 2014;98 (Suppl 1):S5-S13.

15. Nicholson GP, Strauss EJ, Sherman SL. Scapular notching: recognition and strategies to minimize clinical impact. Clin Orthop Relat Res. 2011;469:2521-2530.

16. Luc Favard, Christophe Levigne, Cecile Nerot, Christian Gerber, Lieven De Wilde, Daniel Mole Reverse Prostheses in Arthropathies With Cuff Tear Are Survivorship and Function Maintained Over Time? Clin Orthop Relat Res. 2011;469:2469-2475. 